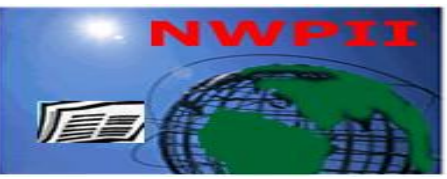

American Journal of Biomedical Sciences

ISSN: 1937-9080

nwpii.com/ajbms

\title{
Assessment of the Levels of Parathyroid Hormone, Oestrogen and Selected Bone Minerals in Menopausal Women
}

\author{
Oluboyo, A.O, Anaenye, C.V, Oluboyo, B.O, Ajayi F.O
}

Department of Medical Laboratory Science, College of Medicine and Health Sciences, Afe Babalola University, Ado Ekiti, Ekiti State, Nigeria.

"Corresponding Author

Dr A.O Oluboyo

Department of Medical Laboratory Science

College of Medicine and Health Sciences

Afe Babalola University, Ado Ekiti

Ekiti State

Nigeria

Email: oluboyoao@abuad.edu.ng

Received:27 August 2018;| Revised:31 August 2018; | Accepted:08 December 2018

\begin{abstract}
Menopause is associated with various physiological and biochemical changes that have effects on bone minerals and their metabolism. There have been a lot of complaints about bone pains and bone related problems especially among middle aged women. Thus, the work was designed to assess and compare the levels of parathyroid hormone (PTH), oestrogen and selected bone minerals (calcium and phosphate) in preand post-menopausal women. A total of one hundred subjects were investigated. They comprised fifty premenopausal women within the ages of 20 years and 45 years and fifty post-menopausal women within the ages of 50 years and 65 years. The levels of parathyroid hormone, oestrogen, calcium and phosphate were measured in the subjects. Parathyroid hormone and oestrogen were analyzed using enzyme immunoassay technique while calcium and phosphate were analyzed using spectrophotometric method. The results showed that parathyroid hormone, calcium and phosphate were significantly increased $(\mathrm{p}<0.05)$ while there was decrease in oestrogen in post-menopausal women compared with premenopausal women. PTH and oestrogen correlated significantly at $(\mathrm{p}<0.01)$ in both pre- and post menopause. This study concluded that postmenopausal women have increased serum levels of parathyroid hormone, calcium and phosphate but decreased serum level of oestrogen. Significant positive correlation exists between PTH and oestrogen in both pre- and post menopause but no significant relationship between PTH and oestrogen with calcium and phosphate.
\end{abstract}

Keywords: Parathyroid hormone, Phosphate, calcium, Oestrogen, Menopause 


\section{Introduction}

Menopause is associated with various physiological and biochemical changes that have effects on bone minerals and their metabolism. It has been shown that post-menopause is the most common cause of osteoporosis because of the effects of oestrogen deficiency, which increases the rate of bone re-modelling, resulting in high turnover bone loss ${ }^{[1]}$. It has been shown that after menopause, the woman loses an average of three percent of bone mineral density every year which leads to osteopenia and finally osteoporosis [2]. Osteoporosis occurs due to a defect in attaining peak bone mass or it can be as a result of accelerated bone loss. In normal individuals, bone mass increases during skeletal growth to reach a peak between the ages of 20 years and 40 years but falls later on during their lifetime. In women there is an accelerated phase of bone loss after menopause due to oestrogen deficiency, which causes bone resorption ${ }^{[3]}$.

Although oestrogen is present in both men and women, it is usually present at higher levels in women who are of reproductive age. It plays a very significant role in the development of female secondary sexual characteristics and also the regulation of menstrual cycles. Aging is the natural development of changes in structure and function that follow with passage of time in the absence of known disease. A prevailing issue concerning the biology and indications of menopause is its connection to the underlying ageing process ${ }^{[4]}$. Factors such as lifestyle, demographic factors, and attitudes all influence a woman's perception of menopause ${ }^{[5]}$. Some women will have upsetting symptoms, whereas others may cross the transition with few or even no signs or symptoms at all ${ }^{[6,7]}$. Women in Nigeria may not demonstrate all the symptoms experienced by women in other geographical areas ${ }^{[8]}$. Apart from the age of an individual, a number of factors including genetic factors, behavioural factors such as smoking and also obesity are said to be accountable for menopause ${ }^{[9,10,11]}$.

Parathyroid hormone secreted by the parathyroid gland is responsible for the maintenance of serum calcium level. Parathyroid hormone provides a powerful mechanism for controlling extracellular calcium and inorganic phosphate by regulating intestinal resorption, renal excretion and exchange between the extracellular fluid and bone of these ions ${ }^{[12]}$. Excess activity of the parathyroid gland causes rapid absorption of calcium salts from the bones, resulting in hypercalcaemia in the extracellular fluid; so as decrease in the function of the parathyroid gland would cause hypocalcaemia [13]. There have been complaints about bone pains and bone related problems especially among middle aged women. Therefore, the work was designed to assess and compare the levels of parathyroid hormone, oestrogen and selected bone minerals in pre-menopausal and post-menopausal women.

\section{Materials and Methods}

The study was conducted in Ekiti State among one hundred apparently healthy women between the ages of 20years and 65 years; pre-menopausal women within the ages of 20 years and 45 years and post-menopausal women within the ages of 50 years and 65 years. The levels of parathyroid hormone, oestrogen, and selected bone minerals (calcium and phosphate) were assessed. Ethical approval was sought for and obtained at Federal Medical Centre, Ido-Ekiti, Ekiti State. The nature and purpose of research was explained to each participant and their consent was sought before blood samples were collected from them. The detection kit lot number is 3-03-2018.

Parathyroid hormone was determined using the Human Parathyroid Hormone Elisa kits from Melsin, China ${ }^{[14]}$.

Principle: The kit uses Enzyme linked immunosorbent assay-double antibody sandwich. The microelisa strip plate provided in the kit has been coated by purified parathyroid hormone antibody to make solid-phase antibody, Calprotectin was added to the wells, which combines with parathyroid hormone antibody labelled by parathyroid hormone which then becomes antibodyantigen-enzyme-antibody complex. After washing completely to remove the uncombined enzyme, chromogen solution A and chromogen solution B were then added. The colour of the liquid changes into blue, and at the effect of acid, the colour finally becomes yellow. The colour change was then 
measured spectrophotometrically at a wavelength of $450 \mathrm{~nm}$.

Oestrogen was determined using human oestrogen ELISA Kit from MELSIN, China ${ }^{[15]}$.

Principle: The kit uses enzyme linked immunosorbent assay-double antibody sandwich principle to assay oestrogen level in the sample. The micro ELISA strip plate provided in the kit has been coated by purified oestrogen antibody to make solid-phase antibody. Oestrogen was added to the wells which then combined with oestrogen antibody labelled by horse raddish peroxidase (HRP), which then becomes antibody-antigen-enzyme-antibody complex. After washing was done to completely remove the uncombined enzyme, chromogen solution $\mathrm{A}$ and chromogen solution $\mathrm{B}$ were added and the colour of the liquid changed to blue. Due to the effect of acid, the colour finally becomes yellow. The colour change was measured spectrophotometrically at a wavelength of $450 \mathrm{~nm}$.

Calcium was assayed using O-Cresolphthalein complexone without deproteinization from Randox, United Kingdom ${ }^{[16]}$.

Principle: Calcium ions form a violet complex with O-Cresolphthalein Complexone in an alkaline medium which is photometrically measured.

Phosphorus was assayed using FiskeSubbarow Method from QCA, Spain ${ }^{[17]}$.

Principle: Phosphate ion reacts with molybdate to produce phosphor-molybdate which is finally reduced to molybdenum blue which is photometrically measured.

\section{Statistical analysis}

Results obtained were subjected to statistical analysis using statistical package for the social sciences (SPSS) (version 21.0 software, SPSS Inc. Chicago, Illinois, USA). All parameters were expressed as mean \pm standard deviation (SD). The student's t-test and correlation were the tools of choice used for comparing the mean between the pre and post- menopausal women. Correlation of the parameters was also done to determine the relationship between the parameters. Values were taken to be statistically significant at $p \leqslant 0.01$ or 0.05 .

\section{Results}

The results of the assessment of parathyroid hormone and other parameters in pre-menopausal women and post-menopausal women are presented in tables.

Table 1 shows the mean \pm standard deviation (SD) when parathyroid hormone and other biochemical parameters were compared in premenopausal women and post-menopausal women. Parathyroid hormone, calcium and phosphate were significantly increased at $(\mathrm{p}<0.05)$ in postmenopausal women. There was no significant decrease in oestrogen in post-menopausal women.

Table 2 shows the correlation of PTH with other parameters in pre-menopausal women. PTH and oestrogen correlated significantly at $(\mathrm{p}<0.01)$. There was no significant correlation between PTH and the other parameters.

Table 3 shows the correlation of PTH with other parameters in post-menopausal women. PTH and oestrogen correlated significantly at $(\mathrm{p}<0.01)$. There was no significant correlation between PTH and the other parameters.

Table 1: PTH, Oestrogen and bone minerals in pre-menopausal and post-menopausal women

\begin{tabular}{lllll}
\hline Parameters & Pre-menopausal & Post-menopausal & $\mathrm{t}$ & $\mathrm{p}$-value \\
\hline PTH $(\mathrm{pg} / \mathrm{ml})$ & $70.70 \pm 47.42$ & $159.09 \pm 65.24$ & -7.749 & $<0.01^{*}$ \\
Oestrogen $(\mathrm{pmol} / \mathrm{l})$ & $5.81 \pm 3.60$ & $5.25 \pm 3.60$ & 0.777 & 0.439 \\
Calcium $(\mathrm{mmol} / \mathrm{l})$ & $2.17 \pm 0.11$ & $2.44 \pm 0.24$ & -7.337 & $<0.01^{*}$ \\
Phosphate $(\mathrm{mmol} / \mathrm{L})$ & $1.05 \pm 0.16$ & $1.57 \pm 0.31$ & -10.583 & $<0.01^{*}$ \\
\hline
\end{tabular}

Values are given as Mean \pm Standard deviation (S.D.)

$\mathrm{N}=50$ for each group

*Significant at $\mathrm{p}<0.01$ 
Table 2: Relationship between PTH and oestrogen with calcium and phosphate in pre-menopausal women

\begin{tabular}{lcc}
\hline Parameters & $\begin{array}{l}\text { Parathyroid hormone } \\
\mathrm{r}(\mathrm{p} \text { value })\end{array}$ & $\begin{array}{l}\text { Oestrogen } \\
\mathrm{r}(\mathrm{p} \text { value })\end{array}$ \\
\hline PTH $(\mathrm{pg} / \mathrm{ml})$ & 1 & $0.424^{* *}(<0.01)$ \\
Oestrogen $(\mathrm{pmol} / \mathrm{L})$ & $0.424^{* *}(<0.01)$ & 1 \\
Calcium $(\mathrm{mmol} / \mathrm{L})$ & $0.186(0.195)$ & $-0.093(0.520)$ \\
Phosphate $(\mathrm{mmol} / \mathrm{L})$ & $0.110(0.446)$ & $-0.139(0.337)$ \\
\hline
\end{tabular}

Key: ** correlation is significant at the 0.01 level

Table 3: Relationship between PTH and oestrogen with calcium and phosphate in post-menopausal women

\begin{tabular}{llc}
\hline Parameters & $\begin{array}{l}\text { Parathyroid hormone } \\
\mathrm{r}(\mathrm{p} \text { value })\end{array}$ & $\begin{array}{l}\text { Oestrogen } \\
\mathrm{r}(\mathrm{p} \text { value })\end{array}$ \\
\hline PTH $(\mathrm{pg} / \mathrm{ml})$ & 1 & $0.528^{* *}(<0.01)$ \\
Oestrogen $(\mathrm{pmol} / \mathrm{L})$ & $0.528^{* *}(<0.01)$ & 1 \\
Calcium $(\mathrm{mmol} / \mathrm{L})$ & $0.098(0.497)$ & $-0.021(0.886)$ \\
Phosphate $(\mathrm{mmol} / \mathrm{L})$ & $-0.028(0.850)$ & $-0.161(0.265)$ \\
\hline
\end{tabular}

Key: ** correlation is significant at the 0.01 level

\section{Discussion}

This study observed significant increase in parathyroid hormone, calcium and phosphate but decreased oestrogen in post-menopausal women compared with pre-menopausal women. This is in agreement with the works which reported elevated levels of parathyroid hormone, calcium and phosphate in post-menopausal women ${ }^{[18,19,20]}$. Their reports also showed that menopause brings about a decline in the production of oestrogen and also implicated elevated levels of calcium and inorganic phosphate in post-menopausal women. Increase in calcium and phosphate levels in post-menopausal women has also been reported in the South eastern part of Nigeria ${ }^{[21]}$. It has been shown that there was a significant correlation between parathyroid hormone and oestrogen in both pre-menopausal women and post-menopausal women. Parathyroid hormone plays a key role in homeostasis of calcium and may affect skeletal health even within its clinically normal range ${ }^{[22]}$. The serum parathyroid hormone level was significantly higher in postmenopausal women compared with pre-menopausal women in this study and this is consistent with previous works ${ }^{[23,24]}$. It has been shown that levels of parathyroid hormone increases with age in women and it correlate significantly with increased bone turnover. Oestrogen is the primary female sex hormone, responsible for the development and regulation of the female reproductive system and secondary sex characteristics. In this study, serum oestrogen levels were lower in post-menopausal women when compared to pre-menopausal women. It was also shown that there was a significant correlation between oestrogen and parathyroid hormone in both pre-menopausal and postmenopausal women in this study. This is because both oestrogen and parathyroid hormone have effects on the bone in post-menopausal women. Oestrogen deficiency leads to its loss of effects on intestinal and renal handling of water, leading to loss of calcium, which then brings about a compensatory increase in the parathyroid hormone, causing calcium to be released from the bones, elevating its levels in serum.

In this study, the serum calcium level was significantly higher in post-menopausal women compared with pre-menopausal women which agrees with previous findings ${ }^{[18,20]}$. Serum calcium can increase in post-menopausal women due to the fact that ageing and menopause induces low levels 
of oestrogen and increased levels of parathyroid hormone leading to the release of calcium ions in the bones, causing elevated levels of the ions in the serum ${ }^{[20]}$. It has been shown that higher levels of serum calcium can be noticed in women in the early ages of menopause (which may be the reason for the levels obtained in this study) but becomes lower at the later ages and this can be due to a decrease in intestinal absorption of calcium ${ }^{[2]}$. Ageing and loss of oestrogen leads to a substantial increase in osteoclastic activity. However, it has been reported that deficiency of calcium and mal-absorption due to hormonal imbalance may lead to disorder of bone mainly osteopenia and osteoporosis ${ }^{[25]}$.

In this study, the serum phosphate level was significantly higher in postmenopausal women compared to pre-menopausal women. This agrees with the study which showed increased levels of the bone minerals ${ }^{[24]}$. The increase in the levels of calcium and phosphate as stated earlier may also be attributable to the increase in the level of PTH because phosphorus and calcium are regulated mainly by two hormones; parathyroid hormone and active form of vitamin $D^{[21]}$. Thus, any interference with action of parathyroid hormone could lead to increasing or decreasing of serum calcium and phosphorus. The effect of age on the parameters between the pre and post-menopausal women was not analyzed in the study because of the difference in age range of the two groups.

\section{Conclusion}

This study concluded that the postmenopausal women had increased serum levels of parathyroid hormone, phosphate, and calcium and decreased serum oestrogen. These may have effects on bone health and may contribute to the reported risk of osteoporosis and low bone mineral density as well as the various complaints about bone pains among postmenopausal women. However, significant positive correlations exist between PTH and oestrogen in both pre- and post menopause but no significant relationship between PTH with calcium and phosphate and oestrogen with calcium and phosphate.

\section{Conflicts of Interest}

The authors declare that there is no conflict of interest.

\section{References}

1 Garnero P, Delmas PD. Contribution of bone mineral density and bone turnover markers to the estimation of risk of osteoporotic fracture in postmenopausal women. $\boldsymbol{J}$ Musculoskelet Neuronal Interact 2004; 4(1): 50-63

2 Surya, Y.P, Ashalata, K., Babu V., Kumari P.K, Nagani M. A study of bone markers (serum calcium, serum phosphorus and serum alkaline phosphatase) in post menopausal women in East Godavari District, Andhra Pradesh, India. Journal of Dental and Medical Sciences 2015.14(6),1-3.

3 Nordin , B.C., Need A.G, Moris, H.A.,O'Loughlin, P.D., Horowitz, M. Effect of age on calcium absorption in post menopausal women.The American Journal of Clinical Nutrition 2004. 80(4),998-1002.

4 Kushwaha S; Chawla P. Impact of supplementation of drumstick (Moringa oleifera) and amaranth (Amaranthus tricolor) leaves powder on menopausal symptoms of postmenopausal women. International Journal of Scientific and Research Publications 2015. 5(1) ISSN 2250-3153.

5 Gold EB, Sternfeld B, Kelsey JL, Brown C, Mouton C, Reame N, Salamone L, Stellato R. Relation of demographic and lifestyle factors to symptoms in a multi-racial/ethnic population of women 40-55 years of age. $\mathbf{A m ~} \mathbf{J}$ Epidemiol 2000; 152(5): 463-473

6 Avis NE, Stellato R, Crawford S, Bromberger J, Ganz P, Cain V, Kagawa-Singer M. Is there a menopausal syndrome? Menopausal status and symptoms across racial/ethnic groups. Soc Sci Med 2001; 52(3): 345-356 [PMID: 11330770]

7 Brzyski RG, Medrano MA, Hyatt-Santos JM, Ross JS. Quality of life in low-income menopausal women attending primary care clinics. Fertil Steril 2001; 76(1): 44-50 [PMID: 11438318] 
8 Jagun, OE Oladapo, O.T; Olatunji A.O. Prevalence of postmenopausal symptoms in gynaecological practice in Nigeria. Tropical Journal of Obstetrics and Gynaecology 2012. 29(1): 223-250.

9 Murabito JM, Yang Q, Fox C, Wilson PW, Cupples LA. Heritability of age at natural menopause in the Framingham Heart Study. $\boldsymbol{J}$ Clin Endocrinol Metab 2005; 90(6): 34273430 DOI: $10.1210 /$ jc.2005-0181

10 Parente RC, Faerstein E, Celeste RK, Werneck GL. The relationship between smoking and age at the menopause: A systematic review. Maturitas 2008; 61(4): 287-298 DOI: 10.1016/j.maturitas.2008.09.021

11 Palmer JR, Rosenberg L, Wise LA, Horton NJ, Adams-Campbell LL. Onset of natural menopause in African American women. $\mathbf{A m ~} \mathbf{J}$ Public Health 2003; 93(2): 299-306 [PMID: 12554590 PMCID: PMC1447734]

12 Guyton, A.C; Hall, J. E. Functions of the ovarian Hormones. In Guyton \& Hall, Textbook of Medical Physiology, 11th ed. Philadephia PA: Saunders, pp. 2006. 991-997

13 Shoback D. Clinical practice. Hypoparathyroidism. N Engl J Med 2008; 359(4): 391-403 [PMID: 18650515 DOI: $\underline{\text { 10.1056/NEJMcp0803050] }}$

14 Pioszak AA, Xu HE. Molecular recognition of parathyroid hormone by its $\mathrm{G}$ protein-coupled receptor. Proc Natl Acad Sci U S A 2008; 105(13): $\quad 5034-5039$ DOI: $10.1073 /$ pnas.0801027105

15 Reis A, Hecht W, Groger R, Bohm I, Cooper DN, Lindenmaier W, Mayer H, Schmidtke J. Cloning and sequence analysis of the human parathyroid hormone gene region. Hum Genet 1990; 84(2): 119-124 [PMID: 2298446]

16 Leo G . Morin , PH.D. Direct colorimetric determination of serum calcium with oCresolphthalein complexone. American journal of clinical pathology 1974. 61(1):1147.

17 Furchgott, R.F ; DE Gubareff, T. The Determination of inorganic phosphate and creatinine phosphate in tissue extracts. Journal of Biological Chemistry 1956. 22(3): 377-388.

18 Masse PG, Dosy J, Jougleux JL, Caissie M, Howell DS. Bone mineral density and metabolism at an early stage of menopause when estrogen and calcium supplement are not used and without the interference of major confounding variables. J Am Coll Nutr 2005; 24(5): 354-360 [PMID: 16192260]

19 Ashuma, S; Shashi, S;Sachdeva,S. Biochemical markers of turnover; diagnostic and therapeutic principles. Osteoporosis 2005. 3: 305-311.

20 Usoro, C.A; Onyeukwu C.U; Nsonwu A.C. Biochemical Bone turnover markers in post menopausal women in calabar. Asian Journal of biochemistry 2007. 2(2): 130-135.

21 Oluboyo, A .O., Orji ,D.A., Onyenekwe,C.C. Afonne ,O.J.,Oluboyo,B.O.,Ikechebelu,J.E., Okeke A.C, Omo-Emmanuel, K.:Some biochemical parameters in pre and post menopausal women in Nnewi, Nigeria. Journal of Advancement in Medical and Pharmaceutical Sciences 2010.4 (2): 19-21

22 Bhattarai, T; Bhattacharya, K; Chaudhuri; Psengupta, P. Correlation of common biochemical markers for bone turnover, serum calcium, ALP in postmenapousal women,. The Malaysian journal of medical science 2014. 21(1): 58-61.

23 Khosla S, Atkinson EJ, Melton LJ, 3rd, Riggs BL. Effects of age and estrogen status on serum parathyroid hormone levels and biochemical markers of bone turnover in women: a population-based study. J Clin Endocrinol Metab 1997; 82(5): 1522-1527 [PMID: 9141544 DOI: 10.1210/jcem.82.5.3946]

24 Al-Daghri NM, Yakout S, Al-Shehri E, AlFawaz HA, Aljohani N, Al-Saleh Y. Inflammatory and bone turnover markers in relation to PTH and vitamin D status among saudi postmenopausal women with and without osteoporosis. Int J Clin Exp Med 2014; 7(10): 3528-3535 [PMID: 25419393 PMCID: PMC4238474]

25 Khatake P.D; Jadhav S. S; Afroz S.Relation between Serum Calcium, Bone Mineral Density and Blood Pressure in Post menopausal women.International Journal of Recent Trends in Science And Technology, ISSN 2277-2812 E-ISSN 2249-8109. 2013, 7 (3): $86-88$ 